\title{
Exploring Factors Affecting End-user Performance of Information Systems
}

\author{
Ahed Abugabah \\ American University in the Emirates, \\ Business School, Dubai, UAE, 5300
}

\author{
Louis Sanzogni \\ Griffith University, Business School, \\ Brisbane, Australia, QLD 4111
}

\begin{abstract}
Organizations continue to invest increasingly in various types of information systems implementations, such as enterprise resource planning and supply chain management systems, primarily because of the belief that these investments will lead to increased productivity for employees. A present interest has remained in forming accurate insights into how users interact with information systems to perform tasks. As an increasing number of companies have adopted enterprise resource planning systems, there is a need to understand the impact of enterprise resource planning systems on individual job performance. A fundamental question for business managers in various types of firms is how to attain better performance from end users of information systems. Information systems researchers continue to have difficulty telling managers what they need to do to achieve the highest level of performance from end users.

In this paper, therefore, we conjecture that a better starting point to address this issue is to carefully identify all the important factors related to end-user performance with the aim of forming a more inclusive model. Our model has been validated and statistically tested, suggesting a more inclusive site for examining the utilization and impacts of information systems. The findings support the strength of the study model in explaining a large part of variance in user performance. The results indicate that system quality, task technology fit, and information quality are the most important factors that lead to better end-user performance.
\end{abstract}

\section{Introduction}

Organizations continue to invest increasingly in the implementation of various types of information systems (IS), such as Enterprise Resource Planning (ERP) systems and Supply Chain Management (SCM) systems, primarily because of the belief that these investments will lead to increased employee productivity. Since an increasing number of companies have adopted ERP systems, there is a need to understand the impact of ERP on individual job performance.

The evaluation of individual performance from an information systems use standpoint has been an ongoing concern in IS research [31], [61]. However, previous studies that examined the relationship between IS and individual performance reported contradictory results that range from positive to nonsignificant and/or a negative relationships. Consequently, a variety of models and approaches have been proposed by numerous studies to investigate and explain the complex interrelations amongst different factors related to users and IS in an attempt to provide a better understanding of system usage and performance.

The question of how to achieve higher performance through the use of IS in business organizations is a continuing problem within IS research. While organizations continue to invest heavily in these systems, the promise and expectation that they should provide increasing productivity gains has been difficult to realize. For instance, a fundamental question for business managers in various types of firms is how to achieve better performance of IS end users. While much has been written about IS, and about system effectiveness, its impacts, and other relevant topics, most studies thus far have focused either on issues related to user expectations and satisfaction or performance issues at the organizational level [35].

Among other issues, end-user performance has been researched as well, and some answers have been provided. However, the situation is still unclear, especially in relation to which factors lead to greater system impact and/or better performance, how end users can improve their performance utilizing IS, and to which issues vendors and employers should give greater attention in order to maximize benefits and get reasonable returns from their investments in IS.

The relationship between the use of IS and its effect on individual performance has been described by many researchers as complex and multidimensional [31], [53], [55]. As a consequence, IS researchers continue to have difficulty communicating to business managers how to achieve the highest level of performance from end users. As a practical matter, managers want to be able to identify the factors of an information system that can be managed to obtain the highest end-user performance [44]. Although this is acknowledged and implied in end-user computing studies, end user performance, especially user performance aspects such as performance efficiency and effectiveness, have not been investigated directly. 
Starting with a major limitation in the IS literature, thus far there has been an oversimplified focus on specific factors relating to user performance [48]. Most of the previous studies relied either on dispositional factors such as attitudes and attention to use, or they focused on situational factors such as user satisfaction, system utilization, and usefulness, with an elaboration on user satisfaction as a popular measure of IS impact [43], [40], [41]; some of these studies investigated different subsets of factors in the traditional systems environment, such as operational systems.

The purpose of this study is to explore factors that affect user performance of the IS, using ERP systems as a context for this study. The study also examines whether ERP systems usage improves user job performance and leads to expected outcomes. We pursue the question by identifying those factors which most likely tend to lead to the highest level of end-user performance and/or shape a significant subset of factors to form a more inclusive model that might be used to investigate IS impacts in further studies.

The study investigates perceived user performance by developing suitable measures related to performance efficiency, effectiveness of end users, and the ability of the information system to help users move towards added creativity and innovation when utilizing them in a complex information systems environment, that is, an ERP systems environment. ERP systems are a set of highly integrated and parametric applications, designed to fit a variety of business firms. These systems have witnessed significant progress in terms of recent investment and research activity [43]. This is the case in higher education especially, where significant resources have been allocated and large investments have been made to move to ERP systems; this represents the largest information systems project adopted by higher education institutions. However, little research has been conducted on ERP systems in universities compared to other environments [34].

\section{Information Systems (IS) and user performance}

Most studies investigating the impact of IS at the user level terminate at user acceptance of the computer technology, the intention to use a system, and system usage, rather than at the performance outcomes. The main reason for this could be attributed to the conventional wisdom that more use leads to better performance. Among these studies, empirical studies that examined the relationship between IS and individual performance effects have reported contradictory results. Furthermore, these studies did not identify which factors lead to better performance and which factors are more significant than the others in relation to improved performance.
Alongside the mixed findings produced by previous studies in terms of the impact of IS usage on user performance, some studies have found that IS usage is positively associated with individual performance [26], [31], [40], while others have found that IS usage has no impact, or even a negative impact, on individual performance [24], [25]. While the evidence about the relationship between IS and individual performance effects is mixed, it is logical to expect that an IS will not contribute to any performance effects unless it is used. In other words, a system must be utilized before it can deliver performance effects [31]. In this sense, utilization means that users of a particular system have the ability to use the system features to facilitate their task performance [43], [44], [60]. This, therefore, signifies the importance of considering different IS models when investigating such a relationship between system factors and user factors rather than relying in one particular perspective, which is the case in many previous studies (i.e., AmoakoGyampah [4]; Venkatesh \& Davis [62]). This helps provide a more inclusive view of the factors that affect and/or lead to the significant effects of IS on user performance as this study does.

In view of the above research, it is expected that with increased IS utilization, there will be an improvement in user performance and, subsequently, a positive relationship should exist between system factors and user performance of ERP systems. Consequently, we proposed that usefulness and ease of use as main determinates of system impact must be necessarily added to our model to examine whether or not these two determinates will affect the relationship between system factors (IQ and SQ) and user performance. This also will help clarify whether the technology itself or other factors will lead to improved performance.

Individual performance impact of IS refers to the actual performance of a user using an IS. DeLone and McLean note that an individual performance impact could also be an indication that an IS has given the user a better understanding of the decision context, has improved his or her productivity, or has changed the user's perception of the importance or usefulness of the IS [23]. A number of prior studies have measured the user performance impact of IS, including improved individual productivity, increased job performance, enhanced effectiveness, and strengthened problem identification capabilities. For example, Gattiker and Goodhue conducted an empirical investigation of the impact of ERP systems on business processes and found that the adoption of ERP systems was positively associated with improved business processes and might include higher quality data for decision making, efficiency gains in business processes, and better coordination among different units within an organization [28]. In another study of Executive Information Systems 
(EIS), the frequency and duration of EIS use were shown to increase the impact of decision-making at the individual level, such as decision-making speed, problem identification speed, and the extent of analysis in decision-making. Furthermore, system usage has a direct positive effect on individual perceived performance impacts, such as the perceived impact of performance, productivity, and effectiveness of the job [40].

\section{Foundation and Model Development}

A noticeable amount of research was associated with end-user evaluation of IS. As a result, several models have appeared in the IS literature. An early study was that of Davis who offered the Technology Acceptance Model (TAM), linking usefulness and ease of use for technology acceptance and impact on user factors such as usage and usage behavior [20]. A subsequent study was that of DeLone and McLean, henceforth the D\&M model, which presented six interrelated dimensions of IS success: system and information quality, system use, user satisfaction, individual impact, and organization impact [22]. Finally, the Task Technology Fit (TTF) model placed the focus on fitness between user needs, task requirements and technology characteristics [29], [31]. As a result of these streams of IS models emerging, the literature review of IS and user performance was classified by IS researchers accordingly. For example, much of the body of the literature was divided into two types: TTF and D\&M studies [30]; [43]; [44]. However, we noticed that other researchers have recently incorporated TAM studies to these classifications, as TAM studies offer another perspective from which one can look at system and user factors [67]. The link between IS and user performance can be clearly explained by discussing the main foundation of the previous literature, which at the same time shapes the foundation of this study as well. Therefore, the foundation of this study is based on the above models as will be discussed in the following sections.

\subsection{The link between TTF and user performance}

Goodhue suggested the TTF model to understand the linkage between IS and individual performance [29]. The TTF model is founded on the notion that when user task characteristics and IS characteristics fit well together, both utilization of the system and user performance will be high. That is to say, when a technology has exactly the functionality needed to complete the required actions for the task, better performance should result [30]. The TTF presumes that the performance impacts are dependent upon the fit between three constructs: technology characteristics, task requirements, and individual abilities. Thus, it is not the technology in isolation that affects performance. Therefore, we should expect that any given characteristics of a technology would have different impacts on performance, depending upon the task requirements or type of user.

Goodhue and Thompson [31] have shown that user evaluations of TTF are statistically linked to perceived performance [30]. Goodhue and Thompson found empirical support for the relationships of TTF and performance, as well as utilization and performance [31]. The specific information systems and technology characteristics for which they tested were: information quality, locatability, authorization, system reliability, and ease of use. While the TTF model does not tell us which characteristics of IS lead to highest levels of user performance, it does suggest some constructs relevant to the investigation of our research question.

Several researchers have used the TTF model to explain the impact of IS and task characteristics on individual performance [31]; Klaus, Gyires, \& Wen, 2003; [30]. The associated relationships between TTF factors, such as compatibility, locatability and adequacy, reflect the consistency between user needs, often termed 'task requirements', and the technology used to perform these tasks. Thus, the consistency of the system features with user needs will result in better performance [31]. Empirically, TTF factors have been found to directly affect performance [41], and system users will reflect TTF in their evaluations, so those evaluations should predict perceived performance.

To sum up, the TTF model continues to evolve and there are some different versions of TTF-based models as well [25]. In addition, it has been suggested that TTF can be extended with other related IS concepts to provide a more comprehensive explanation regarding the relationships between technology, task, performance and the utilization of technology. For example, utilization is influenced by TTF through the concepts of perceived usefulness, which is one of the core concepts of the TAM [29]. In addition, extended TAM with TTF constructs and the TTF model with self-efficacy constructs are all examples of extending the TTF model with other IS models [25]. Accordingly, although TTF is not as well developed as TAM, the concept of TTF is an important user evaluation construct in predicting the utilization and the impacts of a particular technology [67].

\subsection{The link between TAM and user performance}

The Technology Acceptance Model (TAM) has emerged as a powerful and parsimonious model that 'belongs' to the IS field and represents the 
antecedents of technology usage [20]. The TAM was proposed to investigate technology adoption behaviors, and two constructs that influence a user's use of technology are: perceived usefulness (PU), and perceived ease of use (PEOU). PU is defined as "the degree to which a person believes that using a particular system would enhance his or her job performance", while PEOU is defined as "the degree to which a person believes that using a particular system would be free of effort" [21]. PEOU is thought to influence the PU of the system [20]. Further, the easier it is to use a technology, the greater the expected benefits from the technology with regard to performance enhancement [4]. Hence, the TAM is specifically meant to explain computer usage.

Since its inception, TAM has served as the basis for several researches aimed at examining usage intentions and the behavior of IS users [62]. Researchers used TAM to explain system usage and its impact on several factors, such as user behavior, usage behavior, utilization, and net benefits of a system. It has been noted that TAM consistently explains a substantial proportion of the variance (typically about 40\%) in usage intentions and behavior [62]. Researchers also found support for both PU and PEOU being determinants of systems usage and impacts. In other words, both PU and PEOU are related to performance impacts of a given system as perceived by the system users.

In the TAM literature, PEOU has been found to influence user's behaviors and system usage, either directly or indirectly, through the system's usefulness; also, system usage is found to be related to system impacts in many IS studies [4].

PU, on the other hand, refers to whether or not a system delivers accurate, timely, relevant, secure, and valid information to the users [20]; [62]. Therefore, using the system will improve job performance, productivity, effectiveness and quality of work. As observed by Amoako-Gyampah, a person's willingness to interact with a particular system is already considered useful [4]. Thus, it is expected that users will adopt a system if they perceive that the system will assist them to attain desired performance outcomes.

In the IS literature, PU and PEOU are interrelated and used together in most research aspects as they affect each other in individual aspects [20]. PU is viewed as a term related to individual impacts, such as improved individual productivity and performance [55]. Furthermore, both terms are related to IS and IQ. For example, in many studies IQ, SQ, and PU were found to be related to one another; moreover, the higher the level of IQ and SQ, the more useful the system [4], [5], [44], [61].

PEOU sometimes explains the variance in PU, while at the same time it influences system use and PU [20]; [57]. Doll and Torkzadeh reported significant relationships between PEOU, timeliness, accuracy, and IQ in general. Other studies, however, showed mixed results [26]. Another noticeable result in an ERP system environment was that ERP users tend to rate the systems as less useful if they find the systems difficult to use. In this study, both PU and PEOU are used to examine how they affect the relationship between SQ and IQ and how they affect user performance both directly and indirectly by intermediating the relationship between system factors such as SQ, IQ and TTF, as well as perceived user performance [59].

\subsection{The link between the D\&M model and user performance}

DeLone and McLean developed the multidimensional IS success model which aimed to investigate IS success and how user satisfaction of a particular system affects system use and impact [22].

Since its development, the IS success model and its constructs have been tested by many researchers. For example, Adams, Nelson, and Todd [1] examined the relationship between IQ and system use, while Seddon confirmed the relationship between SQ and user satisfaction, as well as SQ and individual impact [55].

Prior D\&M studies focused on identifying the conditions under which users are satisfied with the systems. The primary argument of these studies is that high levels of user satisfaction lead to high levels of user performance [30]; [31], Howell, Love, \& [61]. Bailey \& Pearson conducted a literature review in an early study to identify influential factors [9]. Other studies extended and tested a questionnaire for investigating the D\&M model in different IS environments and provided evidence of the instrument reliability, content validity, predictive validity, and construct validity of the model constructs [23]; [26].

These early works paved the way for other studies that linked the constructs of the D\&M model, such as system characteristics and user performance. Some of these studies have also focused specifically on clarifying and confirming the relationship between system factors and end-user performance [22]. This argument is also the central point of Igbaria et al.'s nomological net model [40]. Another important study also postulated but did not test the existence of relationships between the constructs of SQ, IQ, system use, user satisfaction, and the constructs of individual and organizational performance [22]. Later, Amoli and Farhoomand [6] developed a questionnaire instrument and empirically tested the relationship between system factors such as IQ, SQ, and user performance, showing the significant impact of systems factors on user performance. These researchers provided validated measures that are relevant to our research 
questions, such as measures of SQ, IQ and IS impacts on user performance. So far, studies on the D\&M model showed that system and information quality can influence user satisfaction directly, the individual's performance indirectly, and, eventually, can affect the whole organization [67]. Other studies also showed a significant relationship between systems factors, including IQ, SQ, and user performance, leading consequently to indirect effects on organizational performance [4].

\subsection{Rationality}

Despite the large number of evaluation studies in the IS literature, demonstrating the effects of IS on user performance has proven extremely difficult [17]. The difficulty of measuring actual performance and/or the limitation of using one model alone led many studies to use multiple perspectives and theories to reach more accurate and rigorous results [53]. We therefore argue that investigating the link between IS and user performance must be done using a multidimensional approach to look at the relevant factors in a broad context of IS, reflecting a common agreement between many researchers (Wu, Chen, \& Lin, 2004; [25]. In fact, incorporating these models will yield more benefits. For example, the TAM and TTF models overlap in a significant way and they could provide a more coherent model if they were integrated; such a model could be even stronger than either standing alone [55]; [56].

In light of these facts, especially the difficulty of objectively measuring performance, researchers have used these models as surrogate measures to predict performance [56]. For that reason, research on extending, integrating and replicating these models and constructs has been appearing in the IS literature to form a better framework by which to evaluate and understand IS impacts on user performance. There are many examples of this; for instance, Palvia [51] developed a new model by integrating the user satisfaction model [22] with other variables such as information accuracy, system adequacy, and timeliness. In another instance, the TAM was extended in order to investigate the actual usage of the systems [62]. The TAM was also incorporated to the TTF model to investigate individual performance [25]. Later on, the same researchers extended the TTF model with a computer self-efficacy construct model explaining the link between the two models to help managers understand how PEOU can be increased. In a similar vein, the TAM and TTF were extended and support was found for the new model [42]; others also found the same support [5]; [15]. Overall, these studies reported that the integrated models have more explanatory power and significant improvement over either model alone [44].

Although, TAM, D\&M, and TTF were not explicitly designed to investigate user performance, they have been the underlying models for several studies in IS research. However, most of these studies have occurred in non-multifunctional environments and in non-field settings [4]. Consequently, what is lacking is a model (or set of models) that explicitly explains the relationships between IS characteristics and user performance [44]. Furthermore, prior studies on these models were carried out in traditional and relatively simple but important environments, such as spreadsheet software, legacy systems, and personal computing [5]. However, with the development and implementation of complex and costly IS that cut across organizational functions such as ERP systems, it is clear that there is an increased need for research that examines these models and extends them to a complex IS environment. ERP systems are unique and comprehensive software packages that seek to integrate the complete range of a business process and functions in order to present a holistic view of the business from a single information and information technology architecture [36]. ERP users' reaction may be different from that of other types of IS users due to ERP's complexity. In saying this, researchers noticed that individual differences of users of a particular system do, in fact, affect the system use and consequently the system impacts on user performance [2]; [59].

In summary, research on TTF, TAM and D\&M models provided a rich inventory of validated measures of different factors related to IS and user performance and also provided a suitable base for end-user performance studies. Using these validated measures seems desirable in the IS literature [4]; [36]). The above facts prompted us to ask the following interesting question: If a particular system is perceived as useful and easy to use by specific users, does that mean performance impacts will also be perceived by the users of the system? Therefore, we argue that incorporating factors from different IS models will offer a significant improvement over either model alone and will help explain significant portion of the perceived performance impacts of the ERP systems.

Our study utilized prior studies and their validated constructs as a starting point for the investigation of our research question. The study combined and statistically validated a model suggesting a more inclusive preview for examining information systems utilization and impacts. It does this by incorporating the key ideas of TTF, TAM, and D\&M models with the aim of exploring the most important factors that affect user performance of an information system within an ERP system environment. This suggests that all of the model's constructs were necessary to predict system impacts on perceived user performance reflecting more explanatory power to better understand system 
utilization and impacts on end-user performance (see Figure 1).

\section{Research Design}

This study explores factors affecting user performance in an ERP bound information system environment. Based on the intent of the study, as well as data obtained from significant literature reviews, the factors that may affect the perceived user performance are illustrated in Fig. 1. The study is mainly based on the external variables covered in the model proposed by DeLone and McLean [22], including SQ, IQ, together with PU and PEOU as research dimensions in the updated TAM [20]; [62]. In addition to extensive literature reviews on IS and user performance, we also conducted in-depth interviews with ERP experts in general, as well as ERP experts in the universities, to further our understanding of the underlying factors influencing users' performance. Data obtained from these interviews also had an effect on shaping the proposed model, as explained later in the methodology section.

\subsection{Hypotheses}

The TTF model postulates that the user's performance will be high when the technology and tasks are consistent [29]. Prior studies showed empirical evidence indicating that user performance was affected as a result of the fitness between the system and user needs [31]; Mathieson \& Keil, 1998). Hence, it is hypothesized that:

H1: TTF is positively associated with perceived user performance.

SQ has been investigated in a significant number of studies and found to affect individual performance in various types of IS environments [11]; [14]; [23]. Hence, it is hypothesized that:

H2: $S Q$ is positively associated with perceived user performance

Researchers claim that IS can vastly improve performance, provided such systems facilitate key processes that lead to more accurate, comprehensive, available, timely, and relevant information [40], [50], [55]; [62]; [65]. Hence, it is hypothesized that:

H3: IQ is positively associated with perceived user performance.

The benefits derived from the use of an IS differ from one user to another based on their demographics. Thus, the impacts of the IS on user performance will differ in terms of demography, including education, age and experience. For example, experience leads to more knowledge, which might influence computer usage [32], influencing utilization and usefulness, and, in turn, affecting system impacts [2], [40]. Therefore, users with different characteristics are likely to experience different IS impacts on their performance. Hence, it is hypothesized that:

H4: User characteristics are positively associated with perceived user performance.

PU refers to whether or not the system delivers accurate, timely, relevant, secure, and valid information to the users [5]; [20]. Therefore, using the system will improve job performance, productivity, effectiveness, and quality of work.

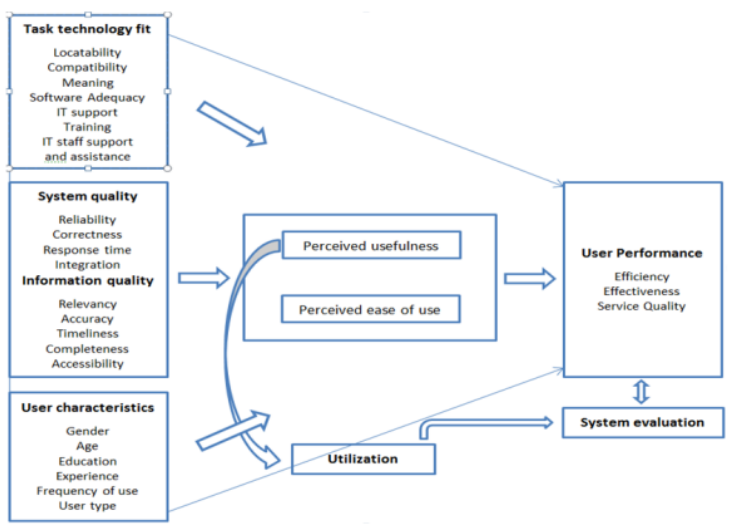

Figure 1. The proposed model

As observed by researchers, users will use a system if they perceive that the system will assist them to attain the desired performance outcomes (Howell et al., 2008). PEOU also has been found to influence system usage, either directly or indirectly through usefulness; further, system usage is found to be related to system impacts in many IS studies [5]. Both PU and PEOU are interrelated [20] and are viewed as related to individual impacts, such as improved individual productivity and performance [58], and are also related to IS and IQ [26]. Doll and Torkzadeh (1988) reported significant relationships between PEOU, timeliness, accuracy, and IQ in general. Other studies, however, showed mixed results. In this study, both PU and PEOU are used to examine how they mediate the relationships between other factors and user performance. Therefore, it is hypothesized that:

H5: PEOU and PU are positively associated with perceived user performance, and will mediate the relationship between the study factors (TTF, SQ, and IQ) and perceived user performance. 


\section{Methodology}

This study adopted a survey method and data were collected by means of a written questionnaire. An intensive study of the relevant literature was undertaken in order to identify the appropriate existing measures for related constructs. Measurement items used in the operationalization of the study instrument (the questionnaire) were adopted from relevant prior research, as shown in Appendix 1. The questionnaire consists of two parts; the first part collected demographic data, while the second part involved questions about the factors, including the fit between the system and task requirements and users' needs, SQ, IQ, PU, PEOU and perceived user performance.

The study was conducted at six different universities in Australia. This was deemed adequate since state universities in Queensland and, indeed, throughout Australia are structured in a very similar way. They have also implemented the same ERP module called 'PeopleSoft'. The names of the universities have been withheld due to our nondisclosure agreement with the executives.

\subsection{Pilot Study and Pre-test}

Although most of the measures used in the instrument were validated in prior research, the research instrument was rigorously pre- and pilot tested. The questionnaire was circulated to three ERP users along with two faculty members in a focus group for review of wording, item order, content and format. The focus group helped to evaluate the overall suitableness of the questionnaire items.

Subsequently, a pilot test was performed. The questionnaire was distributed to 15 participants in three different universities to evaluate ERP impacts on their performance. The data from those users were analyzed and the results of the analysis showed a high level of reliability. The insights acquired from the test were used to make slight modifications to the final questionnaire. The coefficient alphas of all the constructs exceed 0.70 and, where relevant, they also exceed the reliability scores reported in the original studies from which the questionnaire items were adopted, as shown in Table 2. After ensuring the appropriateness of the instrument, the main study was conducted.

\subsection{Sample and Procedures}

Universities invited to participate in the study were contacted by means of a covering letter explaining the purpose of the study. The draft questionnaire and the model were attached to the letter, thus giving the participants a clear idea about the study. This was followed up with a phone call in order to identify a contact person (facilitator) at each of the participating universities to facilitate the study process.

An email was sent to all ERP users in each of the universities to introduce the researcher and the study aims and to request their participation. To protect the participant's confidentiality and to avoid bias, the information on the returned questionnaires was kept strictly confidential.

A total of 408 questionnaires were returned, either by mail or by the contact person in each university. All questionnaires were checked to ensure their usability in the analysis. This resulted in the deletion of 21 of the 408 returned questionnaires and the retention of 387 useable questionnaires. The respondents belonged to various functional areas and were from different backgrounds; they included managers, as well as administrative and system professionals experienced in ERP applications. This helped provide different perspectives about the ERPs and offered a more inclusive view. The questionnaires were coded and given sequential numbers (from 1 to 387) written clearly on the front cover page; the data were entered into the SPSS in the same order to facilitate data correction and ensure accuracy of the data.

\section{Data Analysis}

A multivariate assumption testing analysis was performed to check for violations of the assumptions. The assumptions tested included outliers, linearity, homoscedasticity and independent residuals.

The results presented in Table 1 show that all values of the Durbin-Watson test came very close to 2 , meaning autocorrelation in the residuals was not present. The results also showed that all values are less than 1 for Cook's distances and close to 0 for the leverages [18], confirming that no autocorrelation exists.

\subsection{Normality}

Gaussian distribution is the assumption that each factor and all linear combinations of the factor are normally distributed. Skewness and kurtosis is also a common rule-of-thumb test for normality. Skewness is a statistical measure that tests whether the peak is centered in the middle of the distribution [12], [39]. A positive value of skewness suggests that the peak is off to the left, while a negative value suggests it is off to the right of the curve. For kurtosis, the data are normally distributed if the kurtosis value falls within the +2 to -2 range. The results of the analysis showed that all skew and kurtosis values ranged from 0.003 to 1.15 , confirming that data are normally distributed for all factors in this study [52]. 


\subsection{Collinearity and Multicollinearity}

In practice, the most common level of cut-off points used to determine the presence of multicollinearity are tolerance values of less than 0.10 , or Variable Inflation Factor (VIF) values of above 10 [59]. As illustrated in Table 2, the tolerance values for all variables were above 0.10 , and VIF values for each variable were less than 10 ; therefore, the study did not violate the multicollinearity assumption [17].

\subsection{Assessment of Reliability and Validity}

The reliability and validity of the measurement items were carried out using reliability and factor analysis. The internal consistency reliability was assessed by calculating Cronbach's alpha values. An alpha value of 0.70 or higher is normally considered satisfactory for most purposes [19]. The results showed that the reliabilities of the constructs ranged from 0.84 for PU to 0.97 for User Performance (UP), indicating high reliability, as summarized in Table 2.

Table 1. Independence and Analysis of Outliers

\begin{tabular}{c|ccccccc}
\hline Factors & DV & $\mathrm{R}$ & $\mathrm{R}^{2}$ & S.E & DW & CD & CL \\
\hline TTF & UP & 0.63 & 0.40 & 0.88 & 2.09 & 0.034 & 0.027 \\
TTF & PU & 0.55 & 0.30 & 0.65 & 1.85 & 0.155 & 0.027 \\
TTF & PEOU & 0.64 & 0.41 & 0.68 & 1.79 & 0.093 & 0.027 \\
IQ & UP & 0.69 & 0.47 & 0.83 & 2.10 & 0.037 & 0.024 \\
IQ & PU & 0.67 & 0.46 & 0.57 & 1.76 & 0.035 & 0.024 \\
IQ & PEOU & 0.65 & 0.42 & 0.68 & 1.93 & 0.076 & 0.024 \\
SQ & UP & 0.79 & 0.62 & 0.70 & 2.02 & 0.097 & 0.034 \\
SQ & PU & 0.61 & 0.37 & 0.62 & 1.93 & 0.214 & 0.024 \\
SQ & PEOU & 0.66 & 0.44 & 0.67 & 1.74 & 0.019 & 0.034 \\
PU & UP & 0.75 & 0.57 & 0.75 & 2.10 & 0.155 & 0.035 \\
PEOU & UP & 0.65 & 0.43 & 0.86 & 1.93 & 0.027 & 0.017 \\
DW: Durbin-Watson, CD: Cook's Distance, CL: Centered Leverage, DV: Dependent variables. & \\
\hline \multicolumn{7}{c}{}
\end{tabular}

Table 2. Reliability, Collinearity and Multicollinearity Analysis

\begin{tabular}{ccccccccccc}
\hline Constucts & Nean & S.D & \multicolumn{4}{c}{ Inter correlation between variables } \\
\cline { 4 - 11 } & & & TTF & IQ & SQ & PU & PEOU & UP & Tolerance & VIF \\
TTF & 4.95 & 0.96 & $(0.90)$ & & & & & & 0.43 & 2.3 \\
& & & & & & & & & 0.32 & 3 \\
IQ & 3.60 & 0.61 & 0.69 & $(0.87)$ & & & & & 0.38 & 2.5 \\
SQ & 3.30 & 0.64 & 0.65 & 0.69 & $(0.87)$ & & & & 0.50 & 1.9 \\
PU & 3.90 & 0.78 & 0.54 & 0.59 & 0.61 & $(0.84)$ & & & 0.45 & 2.1 \\
PEOU & 3.30 & 0.89 & 0.62 & 0.63 & 0.67 & 0.54 & $(0.89)$ & & \\
UP & 4.50 & 1.14 & 0.61 & 0.61 & 0.76 & 0.75 & 0.65 & $(0.97)$ & & \\
\hline
\end{tabular}

* Numbers in parenthesis represent Cronbach's alpha. $* * \mathrm{P}<0.01$ level (2-tailed).

\subsection{Validity}

Both convergent and discriminant validity were used to confirm the appropriateness of the measurement obtained for the factors used in the study. Factor analysis was carried out to examine measurement convergent and discriminant validity. Typically, convergent validity is considered to be satisfactory when items load high on their respective constructs (factors). The cut-off point used in this analysis was 0.5 [16]; [28]. All correlations below this point were considered low. As shown in Table 3, all items had high loadings on their respective factors (that is, they were higher than the cut-off criteria of 0.50 ); most items were above 0.70 , demonstrating high convergent validity. However, two items of the TTF construct (Com1 and ITsub1) did not meet the cutoff criteria and thus were removed from any further analysis.

Discriminant validity was tested for a construct using Cronbach's alpha. For a construct to be valid, its Cronbach's alpha should be greater than its correlation with other constructs [16]; [17]. As shown in Table 2, comparison of the correlations with the Cronbach's alphas indicated that this is true for all constructs and, therefore, discriminant validity is satisfied [15].

\section{Discussion and Analysis}

\subsection{The Impact of TTF on User Performance}

TTF was investigated to examine whether or not the ability of the information system to meet users' needs affects user performance, and also to test if the fitness between the information system and task requirements will lead to more improved performance. TTF was measured by locatability, compatibility, meaning, adequacy, and IT support. In the TTF literature it was found that when a system has the functionality needed to complete a task, better performance should result [30].

The results of this study revealed a positive effect of TTF on user performance at $\mathrm{P}<0.05$, demonstrating a significant relationship between TTF and user performance as TTF explains $40 \%$ of the variance in user performance $(F=52, R=0.630)$. Thus, H1 is supported. However, a portion of this effect is still in need of an explanation. Therefore, for the sake of completeness, this study further investigated all TTF measures by analyzing, in more detail, locatability, compatibility, meaning, adequacy, and IT support, and their relationship with user performance.

The findings indicate that among the TTF measures, compatibility, meaning, and adequacy of the systems were more important to user performance, while IT support, including the training provided to users was less effective in influencing user performance. This means that users evaluate the impacts of IT support and training relatively differently, which might be due to the overlap between these factors and/or the different effects of 
each factor associated with the presence interaction of other factors, as noted by other researchers (e.g. see Mathieson \& Keil [49]). In this regard, previous studies also found similar impacts for these measures. For example, other researchers reported similar results to ours for locatability, compatibility and adequacy in producing systems' impacts on user performance, and also similar results to ours for training and IT support [25]; [41]. Furthermore, IT support such as training provided usually takes place at the early stages of system implementation where users train to use the system and to utilize the system's features [42]. The organizations investigated in this study implemented ERP systems more than ten years ago and most users had sufficient system experience with the ERPs; this is explained later in section 6.3 on user characteristics.

This confirms the importance of compatibility and adequacy for the accomplishment of users' tasks, as users attain more benefits when the systems have high compatibility and match their work requirements; these may include reducing the time taken to perform tasks, enhancing performance efficiency, and improving the quality of the work performed.

In light of these facts, it is useful to information system vendors and designers to consider users' needs and concerns in the design of information system packages. In brief, the current study confirms the direct role that TTF plays in explaining the impact of information systems on user performance and demonstrates that TTF is a robust model in which task and technology characteristics significantly determine the correspondence between a system's functionality, user needs, and task requirements [67].

\subsection{The Impacts of SQ on User Performance}

SQ measurements focus on the characteristics and specifications of a target system. Previous studies stated that when the system is perceived as having high quality, the system benefits and the individual impacts would be greater. The study found that a large part of user performance is explained by SQ. This confirms that the greater the $\mathrm{SQ}$, the better the user performance is. The findings of the study indicated that SQ affects user performance and confirmed the main proposition of the D\&M model as SQ performed in a similar fashion as in the original model.
As shown in Table 5, the analysis yielded a regression function $(\mathrm{R}=0.765, \beta=0.765, \mathrm{P}<0.01)$ indicating that SQ explained $58.6 \%$ of the variance in user performance and thus, hypothesis $\mathrm{H} 2$ was supported. SQ was found to be a critical factor that plays an important role in enhancing user performance and helping users to perform tasks more quickly with less time and efforts.

Among SQ measures, correctness and response time are the most significant contributors to user performance $(\beta=0.425,0.193)$ respectively. They help users reduce mistakes in their performance and even help users to correct mistakes when they happen and save time taken to perform tasks, enhancing the quality of user performance.

\subsection{The Impact of Information Quality on User Performance}

Information quality (IQ) measures are very important as they determine the degree to which information is used [6]. More usage in turn will yield more impacts on user performance, which sit at the core of the D\&M model [13]. In this study, and in accordance with IQ literature, IQ measures focus on a number of information characteristics including accuracy, relevancy, timeliness, completeness and accessibility, assuming that IQ will affect user performance as it does in the D\&M model [22]; [26]. Consistent with previous studies, the results of the current study indicated that the impact of IQ on user performance was significant. However, the relationship was not as strong as SQ in term of predicting the variance in user performance [22]. Overall, this study confirmed the importance of the D\&M model in predicting user performance. As shown in Table 6 , the whole model was significant $(\mathrm{R}=0.609, \mathrm{P}<0.01)$, explaining $37.1 \%$ of the variance in user performance $(\mathrm{R} 2=0.371, \beta=0.606)$ and thus, $\mathrm{H} 3$ is supported.

Amongst IQ measures, completeness or the volume of the information was the most significant measure of user performance $(\beta=0.341)$. ERP users give high attention to information completeness as it contributes significantly to their performance. They reported that the completeness of the information available through ERP systems helps them achieve their performance goals and improves the quality of the work performed.

Accuracy was also found to be a very important factor and contributes uniquely to improved user performance $(\beta=0.213)$. It leads to more accurate work with less mistakes and errors as users rely on 
Table 3. Factor Analysis*

\begin{tabular}{|c|c|c|c|c|c|c|c|}
\hline Factors/Items & Loading & Mean & SD & Factors/Items & Loading & Mean & SD \\
\hline TTF & & 4.9 & 0.96 & Corr1 & 0.75 & 3.2 & 0.93 \\
\hline Loc1 & 0.74 & 5.3 & 1.39 & Corr2 & 0.60 & 3.3 & 0.92 \\
\hline Loc2 & 0.81 & 4.9 & 1.39 & \multicolumn{2}{|c|}{$\mathbf{P U}$} & 3.9 & 0.78 \\
\hline Com2 & 0.74 & 5.4 & 1.12 & PU1 & 0.69 & 3.9 & 0.83 \\
\hline Com3 & 0.75 & 5.3 & 1.14 & PU2 & 0.67 & 4.2 & 1.03 \\
\hline ITsub2 & 0.84 & 4.7 & 1.33 & PU3 & 0.76 & 3.7 & 0.92 \\
\hline ITsub3 & 0.85 & 4.8 & 1.31 & PU4 & 0.73 & 3.7 & 0.98 \\
\hline Ade1 & 0.84 & 4.8 & 1.34 & \multicolumn{2}{|c|}{ PEOU } & 3.3 & 0.89 \\
\hline Ade2 & 0.60 & 4.8 & 1.36 & PEOU1 & 0.72 & 3.2 & 1.00 \\
\hline Mea1 & 0.74 & 4.5 & 1.30 & PEOU2 & 0.85 & 3.2 & 0.97 \\
\hline Mea2 & 0.78 & 4.3 & 1.30 & PEOU3 & 0.89 & 3.4 & 0.98 \\
\hline IQ & & 3.6 & 0.61 & & & & \\
\hline Accees1 & 0.71 & 3.5 & 0.90 & \multicolumn{2}{|c|}{ User performance } & 4.5 & 1.14 \\
\hline Access 2 & 0.82 & 3.4 & 0.91 & Effici1 & 0.81 & 4.6 & 1.28 \\
\hline Complet1 & 0.50 & 3.4 & 0.88 & Effici2 & 0.77 & 4.9 & 1.34 \\
\hline Complet 2 & 0.50 & 3.7 & 0.76 & Effici3 & 0.76 & 4.7 & 1.29 \\
\hline Tim1 & 0.53 & 3.6 & 0.86 & Effici4 & 0.76 & 4.6 & 1.32 \\
\hline Tim2 & 0.69 & 3.6 & 0.87 & Effici5 & 0.65 & 4.6 & 1.24 \\
\hline SQ & & 3.3 & 0.63 & Effici6 & 0.78 & 4.7 & 1.32 \\
\hline Integ1 & 0.77 & 3.1 & 0.85 & Effici7 & 0.74 & 4.8 & 1.35 \\
\hline Integ2 & 0.78 & 3.3 & 0.83 & Effici8 & 0.69 & 4.7 & 1.34 \\
\hline Integ3 & 0.58 & 3.2 & 0.99 & Effec1 & 0.71 & 4.5 & 1.38 \\
\hline Relia1 & 0.66 & 3.7 & 0.87 & Effec2 & 0.61 & 4.4 & 1.32 \\
\hline Relia2 & 0.83 & 3.6 & 0.79 & Effec3 & 0.60 & 4.7 & 1.30 \\
\hline Restime1 & 0.73 & 3.3 & 0.96 & Crea1 & 0.91 & 3.9 & 1.52 \\
\hline Restime2 & 0.74 & 3.2 & 0.94 & Crea1 & 0.83 & 3.7 & 1.57 \\
\hline
\end{tabular}

*Only loadings of 0.5 or above are shown

Table 4. Regression analysis for TTF and user performance

\begin{tabular}{lccccccccc}
\hline & \multicolumn{4}{c}{ Multiple regression } & \multicolumn{4}{c}{ *Stepwise regression } \\
\hline Factors & $\mathbf{B}$ & $\mathbf{S . E}$ & $\boldsymbol{\beta}$ & $\mathbf{t}$ & $\mathbf{S i g}$ & $\mathbf{R}$ & $\boldsymbol{R}^{2}$ & $\boldsymbol{\beta}$ & S.E \\
Locatability & 0.007 & 0.049 & 0.008 & 0.149 & 0.882 & & & & \\
Compatibility & 0.302 & 0.064 & 0.290 & 4.72 & 0.05 & 0.570 & 0.325 & 0.307 & 0.938 \\
& & & & & & & & \\
Adequacy & 0.148 & 0.052 & 0.163 & 2.83 & 0.05 & 0.633 & 0.401 & 0.184 & 0.886 \\
IT support & 0.069 & 0.041 & 0.076 & 1.70 & 0.089 & & & & \\
Meaning & 0.201 & 0.049 & 0.229 & 4.07 & 0.05 & 0.620 & 0.384 & 0.237 & 0.898 \\
$\mathbf{R}$ & & 0.630 & & & & & & & \\
$\mathbf{R}^{2}$ & & 0.402 & & & & & & & \\
$\mathbf{F}$ & & 52 & & & & & & &
\end{tabular}


the systems to get accurate information needed to perform their tasks and achieve job goals. This in turn improves efficiency and effectiveness of user performance. Obtaining information on time from

ERP systems also helps users improve their efficiency and reduces the time spent to achieve their tasks. In other words, ERP systems provide accurate, complete and timely information for users, which significantly improve performance.

Lastly, timeliness, or getting the information in a timely manner contributes also significantly to user performance $(\beta=0.197)$. When the system provides information that the users need when they need it, leads to increased system usage and impacts. Overall, the above results of IQ analysis can be useful in implementing and managing information systems. Managers of information systems, vendors and consultants need to pay sufficient attention not only to improve the quality of the systems as a product, but also to improve the quality of the systems' outputs (the information), such as information accuracy, formatting and completeness of information to align with users' requirements [66]. In other words, the characteristics of the information provided by the system play a vital role in affecting the quality of the work and the quality of the work done by users.

Table 5. Multiple and Stepwise regression of SQ and user performance

\begin{tabular}{lccccccc}
\hline \multicolumn{3}{r}{ Nultiple regression } & & \multicolumn{5}{c}{ Stepwise regression } \\
\hline Factor & S.E & $\boldsymbol{\beta}$ & $\boldsymbol{t}$ & Sig & $\mathrm{R}$ & $\mathrm{R}^{2}$ & $\mathrm{~F}$ \\
Constant & 197 & 0.049 & -0.119 & 0.906 & & & \\
$\mathrm{SQ}$ & 0.059 & 0.765 & 23.33 & 0.001 & 0.765 & 0.586 & 544.4 \\
Correctness & & 0.425 & & 0.001 & 0.704 & 0.495 & \\
\hline
\end{tabular}

\subsection{The Impacts of User Characteristics on User Performance}

User characteristics such as computer experience, gender and age were thought to be important factors in IS research [8]. In fact, these factors have not been adequately regarded even in the original TAM and user satisfaction models. Recent studies, however found that user characteristics or what sometimes called "individual differences" are significant factors that help explain information systems usage and impact [8]; [58]; [63]; [68] and consequently has been documented recently in end computer performance and human computer interaction literature (Howell et al., 2008; [7]. The characteristics investigated in this study included gender, experience, education, usage type and type of users. The analysis showed a significant relationship between user characteristics and system impacts $(R=0.281)$, explaining, however, only $7.9 \%$ of the variance in user performance; thus, $\mathrm{H} 4$ is supported. However, the results showed that only gender, education and user type were significant, but the remaining characteristics did not account for any significant variance.

The results of the analysis for user characteristics are interesting. The negative relationship between experience, education and system impacts could be a unique and interesting phenomenon occurring in a specific system's environment, prompting further research on these factors. Other factors, including the type of user (IT professionals and general users) and system usage (frequency of use), also produced interesting findings. Overall, the compelling results of the user characteristics will be discussed in detail in the next paper. We think that discussion of these characteristics is worthwhile and offers new insights for both IS researchers and practitioners.

\subsection{Mediation Effects of PU and PEOU}

Testing the mediation effects of the PU and PEOU on the relationship between study factors (including TTF, SQ, IQ and UC) and user performance is an important part of this study. Baron and Kenny suggested using the Sobel test to test mediation effects [10]. The Sobel test is an approximate significance test for an indirect effect of an independent factor on a dependent factor via a mediator. Thus, a Sobel test was conducted to test whether the relationship between the abovementioned factors was mediated through TAM factors (PU and PEOU). The results of this analysis are presented in Table 7, which shows that there was significant mediation of TAM factors on the relationship between all study factors and user performance.

Table 6. Multiple and stepwise regression of IQ and user performance

\begin{tabular}{lccccccc}
\hline Factors & S.E & $\beta$ & $\mathrm{t}$ & $\mathrm{Sig}$ & $R$ & $R^{2}$ & $F$ \\
\hline Constant & 0.278 & & 1.312 & 0.190 & & & \\
IQ & 0.076 & 0.609 & 15.061 & 0.001 & 0.609 & 0.371 & 227 \\
Completenless & 0.949 & 0.341 & & 0.001 & 0.557 & 0.310 & \\
Accuracy & 0.918 & 0.213 & & 0.002 & 0.597 & 0.356 & \\
Timelimess & 0.900 & 0.197 & & 0.001 & 0.618 & 0.383 & \\
\hline
\end{tabular}

Table 7. Sobel Analysis of the Mediation Effect PU and PEOU

\begin{tabular}{lccccccccc}
\hline Factor & Beta & S.E & $\begin{array}{c}\text { Sobel } \\
\text { Z value }\end{array}$ & Probability & Factor & Beta & S.E & $\begin{array}{c}\text { Sobel } \\
\text { Z value }\end{array}$ & Probability \\
& \multicolumn{1}{c}{} & & & & & & & \\
\hline TTF-PU & 0.551 & 0.034 & 9.05 & $<0.001$ & PEOU-UP & 0.258 & 0.053 & & \\
PU-UP & 0.589 & 0.054 & & & IQ-PU & 0.679 & 0.048 & 7.38 & $<0.001$ \\
TTF-PEOU & 0.621 & 0.037 & 6.80 & $<0.001$ & PU-UP & 0.536 & 0.062 & & \\
PEOU-UP & 0.439 & 0.059 & & & IQ-PEOU & 0.654 & 0.057 & 5.45 & $<0.001$ \\
SQ-PU & 0.605 & 0.050 & 7.41 & $<0.001$ & PEOU-UP & 0.359 & 0.058 & & \\
PU-UP & 0.459 & 0.049 & & & UC-PU & 0.342 & 0.091 & & \\
SQ-PEOU & 0.665 & 0.053 & 4.54 & $<0.001$ & PU-UP & 0.771 & 0.091 & 3.44 & $<0.001$ \\
\hline
\end{tabular}


Table 8. Factors Affecting PU and PEOU

\begin{tabular}{lllllllllll}
\hline \multirow{2}{*}{ Factors* } & $P U$ & \multicolumn{10}{c}{ PEOU } \\
\cline { 2 - 10 } & $\boldsymbol{\beta}$ & $\mathrm{S.E}$ & $\mathrm{Sig}$ & $\mathrm{R}$ & $\mathrm{R}^{2}$ & $\boldsymbol{\beta}$ & $\mathrm{S} . \mathrm{E}$ & $\mathrm{Sig}$ & $\mathrm{R}$ & $\mathrm{R}^{2}$ \\
\hline SQ & 0.297 & 0.622 & 0.001 & 0.605 & 0.366 & 0.337 & 0.671 & 0.002 & 0.665 & 0.442 \\
IQ & 0.292 & 0.591 & 0.001 & 0.654 & 0.428 & 0.251 & 0.597 & 0.001 & 0.749 & 0.561 \\
Frequency of use & 0.195 & 0.572 & 0.002 & 0.682 & 0.465 & & & & & \\
Type of user & 0.126 & 0.567 & 0.001 & 0.691 & 0.477 & 0.199 & 0.614 & 0.001 & 0.732 & 0.535 \\
TTF & 0.139 & 0.563 & 0.012 & 0.697 & 0.486 & 0.272 & 0.633 & 0.001 & 0.710 & 0.504 \\
\hline
\end{tabular}

Overall, the results supported both $\mathrm{H} 5$ and H6 and showed that PU and PEOU play a critical role in mediating the relationship between TTF, SQ, IQ and UC, and user performance. For example, PU improves the way user perceived SQ, IQ and TTF, consequently leading to more system impacts on performance. When the systems are perceived by users as high quality, able to meet user needs and task requirements, and provide high quality outputs, users will tend to perceive the system as useful and easy to use; consequently, this leads to greater system impact and improved performance. This relationship seems to apply in all study factors as shown in the Table 7. As the results showed that TAM factors are very important factors in improving the effects of the other factors on user performance, it would be interesting to investigate which factors predict PU and PEOU the most.

The results showed a positive relationship, $\mathrm{R}=$ 0.660 , which explains $43.6 \%$ of the variance in PU. Similarly, the results also indicated that all the independent factors (TTF, UC, SQ and IQ) predict

PEOU, $\mathrm{R}=0.724$, which explains $52.4 \%$ of the variance in PEOU, as shown in Table 9 below. SQ was the most significant factor in predicting $\mathrm{PU}, \beta=$ 0.297 , presenting the individual contribution of SQ. Furthermore, IQ, usage type, type of user and TTF were found to be significant factors affecting PU as $\beta$ values for these factors were $0.292,0.195,0.126$, and 0.139 , respectively. Similarly, the result indicated that SQ was the most significant factor affecting PEOU and contributed uniquely to PEOU $(\beta=$ $0.337)$. The relative importance of these factors is listed in Table 8 below according to their $\beta$ values; almost all the same factors operate here as they did with PU. This signifies the importance of these factors in determining system usage and impacts, as $\mathrm{PU}$ and PEOU in turn magnify the system impacts on user performance [45]; [64].

\section{Conclusions, Contributions and Implementations}

This study investigated factors affecting user performance of information systems. The study commenced with a review of past IS and user performance literature. As a result, it was established that gaps existed in previous studies and in understanding the importance of investigating the impacts of information systems on user performance.
The literature review revealed that user performance has been investigated in previous studies in different information systems settings [44]. However, it was not investigated in such a way that explicitly analyses the impacts of different factors on user performance. This is the first study to investigate directly all of the links for information systems in general, and ERP systems in particular and user performance.

As such, prior research applied different IS models that were validated for different purposes in IS literature, such as the TTF, TAM and D\&M models [35]; [44]; [47]; Mathieson \& Keil, 1998; [57]. This study took lessons from previous studies in order to build up a new model that is suitable to better understand the impact of information on user performance by shifting the focus from organizational and technical aspects to user and system aspects [3]; [36]; [15]. The most important factors that affect user performance are SQ, TTF and IQ respectively, given the relative importance for the measures that consist of each factor as discussed earlier in this study. Interestingly, we found that SQ was not only the most important factor affecting user performance, but it was also the most significant factor predicting both PU and PEOU of the system. In other words, SQ affects user performance both indirectly and directly through PU and PEOU. This signifies the importance of this factor to be considered by information systems vendors and practitioners when designing and evaluating information systems.

The findings of this study provide important contributions and outline implications for researchers and practitioners. For researchers, the study confirmed some common factors that can be used to investigate various types of information systems such as SQ and IQ [24]. The study provides evidence of the appropriateness of extending IS models as a useful way to give more powerful insights about user aspects and system impacts. Therefore, the primary theoretical contribution of this study to IS theory is the consolidation of three different models and the explanation of the interrelationships between them. The analysis showed that the combined model was powerful in explaining a large part of the variance in user performance, as similar studies that used these models individually did not show the same degree of power [61].

This also helped improve the understanding of the relationship between these individual models by clarifying the overlapped models and the interrelationships between factors drawn from these models [24], [66]. For example, several significant relationships between these models were found, such as the relationship between TTF and D\&M models. The findings indicated that TTF, SQ and IQ as one combined model yielded the best exploratory model to explore the relationship between information 
systems and user performance; as a whole model, they bring unique results, confirming the rationality of integrating these models.

The original TAM relationships were confirmed. Both the Sobel test and regression analysis showed the significance of PU and PEOU towards system usage. Evidence existed for a stronger dependence of users on utilization than on lower complexity when using ERP systems. Both Sobel $Z$ value and $\beta$ coefficients are higher for relationships with PU than those with PEOU. Research on TAM has investigated this issue. This indicates that as users gain experience with ERP systems, PEOU is overshadowed by other factors [63]. This is an interesting result in terms of user characteristics and will be further investigated in detail in the next paper. We suggest that discussion of these characteristics is worthwhile and would add new dimensions for both ERP researchers and practitioners.

The current study opens up various paths and avenues for future research. The factors used in this study and their conceptualization can be used for further investigation of IS in different industries. The study also gained evidence to support the view that IQ and SQ are significant determinants of utilization and usefulness, and are obtained when using IS. However, SQ exhibited a stronger effect than IQ [27]. Prior research defined the nature of the relationships between SQ and individual performance using the D\&M model, which collected information on SQ, IQ, user satisfaction and attitudes, organizational, and individual impacts. It has been articulated by many researchers that PU must precede system impacts and benefits, although it may not necessarily cause them [33]; [55]; suggesting that PU should be added to the above factors when investigating user performance. This was confirmed in the current study and referred to above in the explanation of the system impacts through PU and PEOU

The results of this study provide evidence that the associated impacts of PU and PEOU are overstated in terms of their effects on user acceptance. This depends on the factors of interest that are investigated, such as IT support, training, and adequacy, as these factors are important in affecting PU and PEOU.

For practitioners, this study demonstrated the importance of TTF in explaining information systems impacts on user performance. Prior research relating to TTF has mainly focused on IT-centric factors, such as user satisfaction and users' attention to use an IS. The results of the current study, however, suggest that extending the focus to other factors, such as IQ and SQ, is important in determining performance impacts and utilization of information systems. Therefore, systems' designers and practitioners should not only focus on user satisfaction and PU, but also give serious consideration to the TTF and system factors, such as functionality and response time, from a users' perspective when planning, designing, and implementing new systems.

The results of this study may contribute to our knowledge of whether understanding user characteristics and their interaction will lead to better utilization and usefulness of information systems. This knowledge might have some bearing on the resources spent for user interface design and user training. For example, we found that systems that are perceived as easy to use prompted a more positive response from those with little computer experience than from others with more computer experience. As such, if the ERP users are predominantly individuals with little computer experience, the system designers should invest more in making the systems easier to use so as to facilitate greater system impacts and benefits.

In saying this, it is worth mentioning that training and support for users should vary according to their needs. Further, trainers should pay attention to the evolution of trainees' perceptions and the influence of ERP systems. Specifically, in the early stage of the system use, ease of use is more important. Therefore, trainers can develop specific tactics, such as focusing on how to use the system; once trainers realize users are no longer newcomers to the system, the training program should accordingly focus on usefulness to meet the users' needs allowing them to explore the functional potentials of the ERP system of interest.

Finally, there has been a general lack of awareness about the importance of evaluating performance impacts from a user perspective. Rather, the main focus of previous studies was on success factors and implementation issues and/or on user acceptance and satisfaction, which are insufficient to evaluate the system impacts on performance. For example, user satisfaction measures users' opinions about the system, but not about the usability and impact. Scholars distinguish between user satisfaction and usability as part of human-computer interaction. This study underscores the importance of this issue and presents a new synthesized model for evaluating the value of information systems at the user level, which logically leads to an evaluation of the benefits of the systems in organizations.

\section{Limitations and Research Directions}

As with most research, this study has some limitations. Although the findings of this study contribute to a better understanding of the factors affecting user performance and explain a large portion of the variance in user performance, there is a considerable part of the variance that remains 
unexplained. This might be due to other significant factors not included in this study, which suggests a need for further empirical and theoretical investigations to incorporate additional variables and include potentially effective factors that play a significant role in explaining user performance such as task types and the nature of the tasks performed by users.

Though several user characteristics were investigated in this study and selected according to the literature on IS and user aspects, there are additional characteristics that have not been included in this study, such as organizational position and nature of the job. Thus, it would be useful if future research incorporated these additional characteristics to explore other areas that might affect user performance. The study investigated the perceived impacts of information systems only from the users' perspectives. Further research to investigate systems' impacts from the perspectives of supervisors and/or managers may be useful in terms of comparison.

\section{Conflict of interest statement}

We declare that we have no financial and personal relationships with other people or organizations that can inappropriately influence, or be perceived to influence, our work.

\section{References}

[1] Adams, D. A., Nelson, R. R., \& Todd, P. A. (1992). Perceived usefulness, ease of use, and usage of information technology: A replication. Management Information Quarterly, 16(2), 227-247.

[2] Agarwal, R., \& Prasad, J. (1999). Are individual differences germane to the acceptance of new information technologies? Decision Sciences, 30(2), 361-391.

[3] Al-Mashari, M., Al-Mudiningh, A., \& Zairi, M. (2003). Enterprise resource planning: A taxonomy of critical factors. European Journal of Operational Research, 14(6), 352-364.

[4] Amoako-Gyampah, K. (2007). Perceived usefulness, user involvement, and behavioral intention: An empirical study of ERP implementation. Computers in Human Behavior, 23(3), 1232-1248.

[5] Amoako-Gyampah, K., \& Salam, A. (2004). An extension of the technology acceptance model in an ERP implementation environment. Information and Management, 41(6), 731745.

[6] Amoli, E., \& Farhoomand, A. (1996). Structural model of end user computing satisfaction and user performance. Information \& Management, 30(2), 65-73.

[7] Antonis, C. S., \& Pamela, J. J. (Writer) (2007). A comparative examination of individual differences and beliefs on technology usage: Gauging the role of IT. Journal of Computer Information Systems, 47(4), 11-18.

[8] Arning, K., \& Ziefle, M. (2007). Understanding age differences in PDA acceptance and performance. Computers in Human Behavior, 23(6), 2904-2927.

[9] Bailey, J., \& Pearson, S. (1983). Development of a tool for measuring and analyzing computer user satisfaction. Management Science, 29(5), 530-545.

[10] Baron, R. M., \& Kenny, D. A. (1986). The moderatormediator variable distinction in social psychologicalresearch: Conceptual, strategic, and statistical considerations. Journal of Personality and Social Psychology, 51(6), 1173-1182.

[11] Besik, S. (2006). Measuring information quality. (Unpublished doctoral dissertation, University of Illinois, 2006).

[12] Blest, D. C. (2003). A new measure of kurtosis adjusted for skewness. Australian \& New Zealand Journal of Statistics, 45, 175-179.

[13] Bovee, M. (2004). Information quality: A conceptual framework and empirical validation. (Doctoral dissertation, University of Kansas, 2004).

[14] Byrd, T. (1992). Implementation and use of expert systems in organizations: Perceptions of knowledge engineers. Journal of Management Information Systems, 8(4), 97-116.

[15] Calisir, F., \& Calisir, F. (2004). The relation of interface usability characteristics, perceived usefulness, and perceived ease of use to end user satisfaction with enterprise resource planning systems. Computer in Human Behavior, 20, 505-515.

[16] Campbell, D. T., \& Fiske, D. W. (1959). Convergent and discriminant validation by the multitrait-multimethod matrix. Psychological Bulletin, 56, 81-105.

[17] Cohen, L., Manion, L., \& Morrison, K. (2007). Research methods in education: A managerial approach (6th ed.). London: Rutledge Falmer.

[18] Cook, R. D., \& Weisberg, S. (1982). Residual and influence in regression. London: Chapman \& Hall.

[19] Cronbach, J. (1951). Coefficient alpha and the internal consistency of tests. Psychometrika 16, 297-334.

[20] Davis, F. (1989). Perceived usefulness, perceived ease of use, and user acceptance of information technology. Management Information System Quarterly, 13(3), 318340.

[21] Davis, F., Bagozzi, P., \& Warshaw, R. (1989). User acceptance of computer technology: A comparison of two theoretical models. Management Science, 3(8), 982-1003.

[22] DeLone, W., \& McLean, E. (1992). Information systems success: the quest for the dependent variable. Information systems research, 3(1), 60-95. 
[23] DeLone, W., \& McLean, E. (2003). The DeLone McLean model of information system success: A ten-year update. Journal of Management Information Systems, 19(4), 3-9.

[24] Dishaw, M., \& Strong, D. (1999). Extending the technology acceptance model with task-technology fit constructs. Information and Management, 36(1), 9-21.

[25] Dishaw, T., Strong, D., \& Bandy, B. (2002). Extending the task technology fit model with self-efficacy constructs. ACM SIGMIS Database Homepage archive, 3 (2-3), 96-107.

[26] Doll, W., \& Torkzadeh, G. (1988). The measurement of end-user computing satisfaction. Management Information System Quarterly, 12(2), 259-273.

[27] Floropoulos, J., Spathis, C., Halvatzis, D., \& Tsipouridou, M. (2010). Measuring the success of the Greek Taxation Information System. International Journal of Information Management, 30(1), 47-56. doi:10.1016/j.ijinfomgt.2009.03.013.

[28] Gattiker, T., \& Goodhue, D. (2004). Understanding the local-level costs and benefits of ERP through organizational information processing theory. Information \& Management, 41(4), 431-443.

[29] Goodhue, D. (1998). Development and measurement validity of a task-technology fit instrument for user evaluations of information systems. Decision Sciences, 29(1), 105138.

[30] Goodhue, D., Klein, B., \& March, S. (2000). User evaluations of IS as surrogates for objective performance. Information \& Management, 38(2), 87-101.

[31] Goodhue, D., \& Thompson, R. (1995). Tasktechnology fit and individual performance. MIS Quarterly, 19(2), 213-233.

[32] Gravill, J., Compeau, D., \& Marcolin, B. (2006). Experience effects on the accuracy of self-assessed user competence. Information \& Management, 43, 378.

[33] Guimaraes, T., Staples, S., \& McKeen, J. (2007). Assessing the impact from information systems quality. The Quality Management Journal, 14(1), 15-30.

[34] Hellens, L., Nielsen, S., \& Beekhuyzen, J. (2005). Qualitative case studies on implementation of enterprise wide systems. Hershey: Idea Group Publishing.

[35] Hernandez, B., Jimenez, J., \& Martin, J. (2008). Business acceptance of information technology: Expanding TAM using industry sector and technological compatibility. International Journal of Enterprise Information Systems (IJEIS), 4(4), 62-79.

[36] Hong, K., \& Kim, Y. (2002). The critical success factors for ERP implementation: An organizational fit perspective. Information \& Management, 40(1), 25-40.
[37] Howell, M., Love, S., \& Turner, M. (2008). User characteristics and performance with automated mobile phone systems. International Journal of Mobile Communications, 6(1), 1-15.

[38] Huang, K., Lee, Y., \& Wang, R. (1999). Quality Information and Knowledge. Upper Saddle River, NJ: Prentice Hall.

[39] Hutcheson, G. D., \& Sofroniou, N. (1999). The multivariate social scientist: introductory statistics using generalized linear models. UK: Sage.

[40] Igbaria, M., Guimaraes, T., \& Davis, G. (1995). Testing the determinants of microcomputer usage via a structural equation model. Journal of Management Information Systems, 11(4), 87-114.

[41] Klaus, T., Gyires, T., \& Wen, J. (2003). The use of web-based information systems for non-work activities: An empirical study. Human Systems Management, 22(3), 105-114

[42] Klopping, I. M., \& McKinney, E. (2004). Extending the technology acceptance model and the task-technology fit model to consumer e-commerce. Information Technology, Learning, and Performance Journal, 22(1), 35-48.

[43] Kositanurit, B. (2003). An exploration of factors that impact individual performance in an ERP environment. (Unpublished doctoral dissertation, University of Virginia, 2003).

[44] Kositanurit, B., Ngwenyama, O., \& Osei-Bryson, K. (2011). Re-examining information systems user performance: Using data mining to identify properties of IS that lead to highest levels of user performance. Expert Systems with Applications, 38(6), 7041-7050.

[45] Kwasi, A. (2007). Perceived usefulness, user involvement and behavioral intention: An empirical study of ERP implementation. Computers in Human Behavior, 23(3), 12321248.

[46] Larsen, T. J., Sorebo, A. M., \& Sorebo, O. (2009). The role of task-technology fit as users' motivation to continue information system use. Computers in Human Behavior, 25(3), 778-784

[47] Lee, K. C., Kang, I., \& Kim, J. S. (2007). Exploring the user interface of negotiation support systems from the user acceptance perspective. Computers in Human Behavior, 23(1), 220-239.

[48] Liu, Y., Lee, Y., \& Chen, A. (2011). Evaluating the effects of task-individual-technology fit in multi-DSS models context: A two-phase view. Decision Support Systems, 51(3), 688-700.

[49] Mathieson, K., \& Keil, M. (1998). Beyond the interface: Ease of use and task/technology fit. Information \& Management, 34(22), 1-230. 
[50] O'Leary, D. (2000). Enterprise resource planning systems: Systems, life cycle, electronic commerce, and risk. Cambridge: Cambridge University Press.

[51] Palvia, P. C. (1996). A model and instrument for measuring small business user satisfaction with information technology. Information \& Management, 31(3), 151-163.

[52] Punch, K. F. (2005). Introduction to social research: Quantitative and qualitative approaches. London: Sage.

[53] Raghunathan, S. (1999). Impact of information quality and decision making quality on decision quality. Decision Support Systems, 26(4), 275-286.

[54] Schwab, P., \& Cummings, L. (1973). Theories of performance and satisfaction: A review. In L. L. Cummings \& W.E. Scott (Eds.), Readings in organizational behavior and human performance. R. D. Irwin.

[55] Seddon, P. (1997). A respecification and extension of the DeLone and McLean model of IS success. Information Systems Research, 8(3), 240-253.

[56] Shih, H. (2004). An empirical study on predicting user acceptance of e-shopping on the Web. Information \& Management, 41(3), 351-368.

[57] Straub, D., Limayem, M., \& Karahanna, E. (1995). Measuring system usage: Implications for IS theory testing. Management Science, 41(8), 1328-1342.

[58] Thompson, R., Higgins, D., \& Howell, J. (1994). Influence of experience on personal computer utilization: Testing a conceptual model. Journal of Management Information Systems, 11(1), 167-187.

[59] Thong, J., Hong, W., \& Tam, K. (2002) Understanding user acceptance of digital libraries: What are the roles of interface characteristics, organizational context, and individual differences? International Journal of Human-Computer Studies, 57(3), 215-242.

[60] Turel, O., Serenko, A., \& Bontis, N. (2010). User acceptance of hedonic digital artifacts: A theory of consumption values perspective. Information \& Management, 47(1), 53-59.

[61] Turner, M., Kitchenham, B., Brereton, P., Charters, S., \& Budgen, D. (2010). Does the technology acceptance model predict actual use? A systematic literature review. Information and Software Technology, 52(5), 463-489.

[62] Venkatesh, V., \& Davis, F. (2000). A theoretical extension of the technology acceptance model: Four longitudinal field studies. Management Science, 46(2), 186-205.

[63] Venkatesh, V., Morris, M. G., Davis, G. B., \& Davis, F. D. (2003). User acceptance of information technology: Toward a unified view. MIS Quarterly, 27(3), 425-478.

[64] Wang, R., \& Strong, D. (1996). Beyond accuracy: What data quality means to data consumers. Journal of Management Information Systems 12(4), 5-34.

[65] Wier, B., Hunton, J., \& HassabElnaby, H. (2007). Enterprise resource planning systems and non-financial performance incentives: The joint impact on corporate performance. International Journal of Accounting Information Systems, 8(3), 165-190.

[66] Wu, J. H., Chen, Y. C., \& Lin, H. H. (2004). Developing a set of management needs for IS managers: A study of necessary managerial activities and skills. Information \& Management, 41(4), 413-429.

[67] Yen, D., Chin, W., Cheng, F., \& Huang, Y. (2010). Determinants of users' intention to adopt wireless technology: An empirical study by integrating TTF with TAM. Computers in Human Behavior, 26(5), 906915. [68] Ziefle, M., Kunzer, A., \& Bodendieck, A. (2004). The impact of user characteristics on the utility of adaptive help systems. Paper presented at the Proceedings of the 7th international conference on work with computing systems, Kuala Lumpur.

Appendix 1

\begin{tabular}{|l|l|l|}
\hline Constructs & \multicolumn{1}{|c|}{ Measurement Items } & Source \\
\hline \multicolumn{2}{|l|}{ Task technology fit } & $\begin{array}{l}\text { (Calisir \& Calisir, 1992; } \\
\text { Goodhue \& Thompson, } \\
1995) .\end{array}$ \\
\hline Locatability & $\begin{array}{l}\text { It is easy to determine what application is available and where } \\
\text { to do my job. } \\
\text { It is ease to locate the data in the ERP applications that I use. }\end{array}$ & \\
\hline Compatibility & $\begin{array}{l}\text { ERP applications that I use are consistent with my tasks. } \\
\text { ERP applications fit with my work aspects. }\end{array}$ & \\
\hline
\end{tabular}




\begin{tabular}{|c|c|c|}
\hline Constructs & Measurement Items & Source \\
\hline Meaning & $\begin{array}{l}\text { The exact meaning of information obtained from the ERP, } \\
\text { relating to my task, is easy to find out. } \\
\text { The correct meaning of the information is obvious and clear on } \\
\text { the ERP software }\end{array}$ & \\
\hline Adequacy & $\begin{array}{l}\text { The ERP software that the university has meets my task } \\
\text { requirements. } \\
\text { The ERP software is adequate to handle my work processing } \\
\text { needs. }\end{array}$ & \\
\hline IT support & $\begin{array}{l}\text { I get the kind of quality computer-related training that I need. } \\
\text { The IT people I deal with understand my work objectives. } \\
\text { It is easy to get IT support and advice from IT people when I } \\
\text { use ERP applications. }\end{array}$ & \\
\hline \multicolumn{2}{|c|}{ Information quality } & $\begin{array}{l}\text { (Amoli \& Farhoomand, } \\
\text { 1996; DeLone \& } \\
\text { Mclean, 1992) }\end{array}$ \\
\hline Accuracy & Our ERP system provides me with accurate information. & \\
\hline Relevancy & Our ERP system provides relevant information. & \\
\hline Timeliness & $\begin{array}{l}\text { Our ERP system provides me with the information I need in a } \\
\text { timely manner. } \\
\text { The information in our ERP system is timely and updated } \\
\text { regularly. } \\
\text { Getting information from our ERP system on time improves my } \\
\text { work quality. }\end{array}$ & \\
\hline Completeness & $\begin{array}{l}\text { I can find complete information when I need it in our ERP } \\
\text { system. } \\
\text { The information in our ERP system is sufficient to do my work. }\end{array}$ & \\
\hline Accessibility & $\begin{array}{l}\text { The information in our ERP system is easily accessible. } \\
\text { Information in our ERP system is easy retrievable. } \\
\text { Convenience of information in our ERP system saves time in } \\
\text { my job. }\end{array}$ & \\
\hline \multicolumn{2}{|c|}{ Perceived usefulness } & $\begin{array}{l}\text { (Amoako-Gyampah \& } \\
\text { Salam, 2004; Blest, } \\
\text { 2003; Davis, 1989) }\end{array}$ \\
\hline & $\begin{array}{l}\text { Our ERP system is useful for my job performance. } \\
\text { I cannot accomplish my job without the ERP system. } \\
\text { Our ERP system supports me in attaining my overall } \\
\text { performance goals. } \\
\text { Our ERP system makes it easier to do my job. }\end{array}$ & \\
\hline \multicolumn{2}{|c|}{ Perceived ease of use } & $\begin{array}{l}\text { (Amoako-Gyampah \& } \\
\text { Salam, 2004; Davis, } \\
\text { 1989). }\end{array}$ \\
\hline & $\begin{array}{l}\text { Our ERP system is user friendly. } \\
\text { It is easy to learn how to use our ERP system. } \\
\text { I find the ERP system is easy to use. }\end{array}$ & \\
\hline
\end{tabular}




\begin{tabular}{|c|c|c|}
\hline \multicolumn{2}{|l|}{ System quality } & \multirow{2}{*}{$\begin{array}{l}\text { (Amoli \& Farhoomand, } \\
\text { 1996; DeLone \& } \\
\text { McLean, 1992). }\end{array}$} \\
\hline Reliability & $\begin{array}{l}\text { Our ERP system is reliable. } \\
\text { Our ERP system has consistent information. }\end{array}$ & \\
\hline Correctness & $\begin{array}{l}\text { I find it easy to correct the errors related to my work using our } \\
\text { ERP system. } \\
\text { Our ERP system helps me reduce the errors in my job. }\end{array}$ & \\
\hline Response time & $\begin{array}{l}\text { Our ERP system reacts and responds quickly when I enter the } \\
\text { data. } \\
\text { Our ERP system responds quickly to my inquiries. }\end{array}$ & \\
\hline Integration & $\begin{array}{l}\text { Our ERP system allows for integration with other systems. } \\
\text { Our ERP system effectively combines data from different areas } \\
\text { of the university. } \\
\text { Our ERP system is designed for all levels of user. }\end{array}$ & \\
\hline \multicolumn{2}{|c|}{ User performance } & \multirow{4}{*}{$\begin{array}{l}\text { (Amoli \& Farhoomand, } \\
\text { 1996; Antonis \& } \\
\text { Pamela, 2007; Arning \& } \\
\text { Ziefle, 2007; Goodhue } \\
\text { \& Thompson, 1995). }\end{array}$} \\
\hline Efficiency & $\begin{array}{l}\text { I can accomplish my work quickly because of the quality of the } \\
\text { ERP system. } \\
\text { Our ERP system lets me do more work than was previously } \\
\text { possible. } \\
\text { Our ERP system has a positive impact on my productivity. } \\
\text { Our ERP system reduces the time taken to accomplish my tasks. } \\
\text { Our ERP system increases the cases I perform in my job. } \\
\text { Using our ERP system in my job enables me to accomplish } \\
\text { tasks more quickly. } \\
\text { Overall, our ERP system improves my efficiency in my job. } \\
\text { Our ERP improves my performance quality. }\end{array}$ & \\
\hline Effectiveness & $\begin{array}{l}\text { Our ERP helps me solve my job problems. } \\
\text { Our ERP reduces performance errors in my job. } \\
\text { Our ERP system enhances my effectiveness in my job. }\end{array}$ & \\
\hline Creativity & $\begin{array}{l}\text { Our ERP helps me to create new ideas in my job. } \\
\text { Our ERP system enhances my creativity. } \\
\text { Overall our ERP system helps me achieve my job goals. }\end{array}$ & \\
\hline
\end{tabular}

